\title{
Dynamic combinatorial chemistry at the phospholipid bilayer interface
}

Friederike M Mansfeld ${ }^{1}$, Ho Yu Au-Yeung ${ }^{1}$, Jeremy KM Sanders', Sijbren Otto ${ }^{2^{*}}$

\begin{abstract}
Background: Molecular recognition at the environment provided by the phospholipid bilayer interface plays an important role in biology and is subject of intense investigation. Dynamic combinatorial chemistry is a powerful approach for exploring molecular recognition, but has thus far not been adapted for use in this special microenvironment.

Results: Thioester exchange was found to be a suitable reversible reaction to achieve rapid equilibration of dynamic combinatorial libraries at the egg phosphatidyl choline bilayer interface. Competing thioester hydrolysis can be minimised by judicial choice of the structure of the thioesters and the experimental conditions. Comparison of the library compositions in bulk solution with those in the presence of egg PC revealed that the latter show a bias towards the formation of library members rich in membrane-bound building blocks. This leads to a shift away from macrocyclic towards linear library members.

Conclusions: The methodology to perform dynamic combinatorial chemistry at the phospholipid bilayer interface has been developed. The spatial confinement of building blocks to the membrane interface can shift the ringchain equilibrium in favour of chain-like compounds. These results imply that interfaces may be used as a platform to direct systems to the formation of (informational) polymers under conditions where small macrocycles would dominate in the absence of interfacial confinement.
\end{abstract}

\section{Background}

Dynamic combinatorial chemistry [1-3] is a growing field in the general area of systems chemistry [4-11] and revolves around equilibrium mixtures of molecules or supramolecules that can exchange the building blocks from which they are constituted. The resulting dynamic combinatorial libraries (DCLs) are inherently responsive to influences that alter the relative thermodynamic stabilities of the library members. For example, addition of a template (a guest molecule or a biomolecule) to a DCL will result in a stabilization of those library members that bind to the template, inducing a shift in the product distribution, ideally in favour of the best binders and at the expense of the other unwanted library members. This responsiveness makes dynamic combinatorial chemistry an important tool for the discovery of new synthetic receptors [12-21] and ligands for biomolecules

\footnotetext{
* Correspondence: s.otto@rug.nl

${ }^{2}$ Centre for Systems Chemistry, Stratingh Institute, University of Groningen,

Nijenborgh 4, 9747 AG Groningen, The Netherlands

Full list of author information is available at the end of the article
}

[22-25]. Moreover, the technique has potential for the development of catalysts by using a transition-state analogue as a template [26,27]. Molecular recognition in DCLs can also occur between or within library members, enabling the discovery of replicating and/or selfassembling systems [28-38], catenanes [39-41] and the exploration of folding of macromolecules [42-44].

While the vast majority of the work on dynamic combinatorial chemistry is confined to homogeneous solutions and in a few cases, two-phase systems $[14,15,45]$, its application to the chemistry at interfaces is largely unexplored, apart from one example of a dynamic combinatorial approach to bilayer membrane transport [21]. Nonetheless, molecular recognition at interfaces is of extreme importance in many different disciplines, ranging from nanotechnology to cell biology. Furthermore, molecular recognition at interfaces can differ markedly from the corresponding process in bulk solution, as a result of a different microenvironment and confinement in two dimensions [46-48]. This prompted us to develop dynamic combinatorial methodology to allow the use of 
this technique at interfaces. We have focussed our efforts on the phospholipid bilayers that mimic the cell membrane and now report the successful adaptation of reversible thioester chemistry [33,44,49-54] for making DCLs at the lipid bilayer interface. We have developed analytical protocols that enable the monitoring of product distributions of libraries of molecules that are bound to the lipid bilayer. Our results show that the kinetics of thioester exchange are comparable in bulk solution and at the bilayer interface, despite the different microenvironments of these two systems. We also show that the partitioning and two-dimensional organisation of building blocks at the membrane surface can bias the product distributions of the libraries from small mainly cyclic products in bulk solution toward larger linear products at the bilayer.

\section{Results and discussion}

Many different reversible covalent chemistries have now been developed that allow for the construction of DCLs in aqueous solution. The most popular of these are hydrazone and disulfide chemistry [1]. However, both processes have equilibration times that are typically in the range of 2-5 days and sometimes even several weeks [55]. This makes these chemistries less applicable to bilayer systems, many of which have limited physical stabilities. For example, unilamellar vesicles prepared from phospholipids are often only stable for approximately 24 hours. Thus, alternative reversible chemistries are required that allow equilibrium to be reached within this timeframe and under relatively dilute conditions. Literature reports suggest that the equilibration of thioesters in bulk aqueous solution is relatively fast $[33,44,49-54]$, which led us to investigate the potential of this reaction in bilayer vesicle systems. As a model system we chose unilamellar vesicles made from egg phosphatidyl choline.

We have designed a series of simple building blocks, featuring an aromatic core to facilitate analysis of the resulting libraries by HPLC using UV/vis detection (Figure 1). The thioesters were attached either directly to the benzene ring (1a) or connected through a methylene spacer (1b). We have compared the reactivity of both constructs in bulk aqueous solution.

\section{Thioester chemistry in bulk aqueous solution}

The rates of thioester exchange and competing hydrolysis were studied by mixing thioester $\mathbf{1 a}$ or $\mathbf{1 b}$ with $\mathrm{N}$ acetyl-L-cysteine 2 (Figure 1; $\mathrm{p} K_{\mathrm{a}} 9.52$ [56], which is comparable to the $\mathrm{p} K_{\mathrm{a}}$ of exchange product 4 , which is

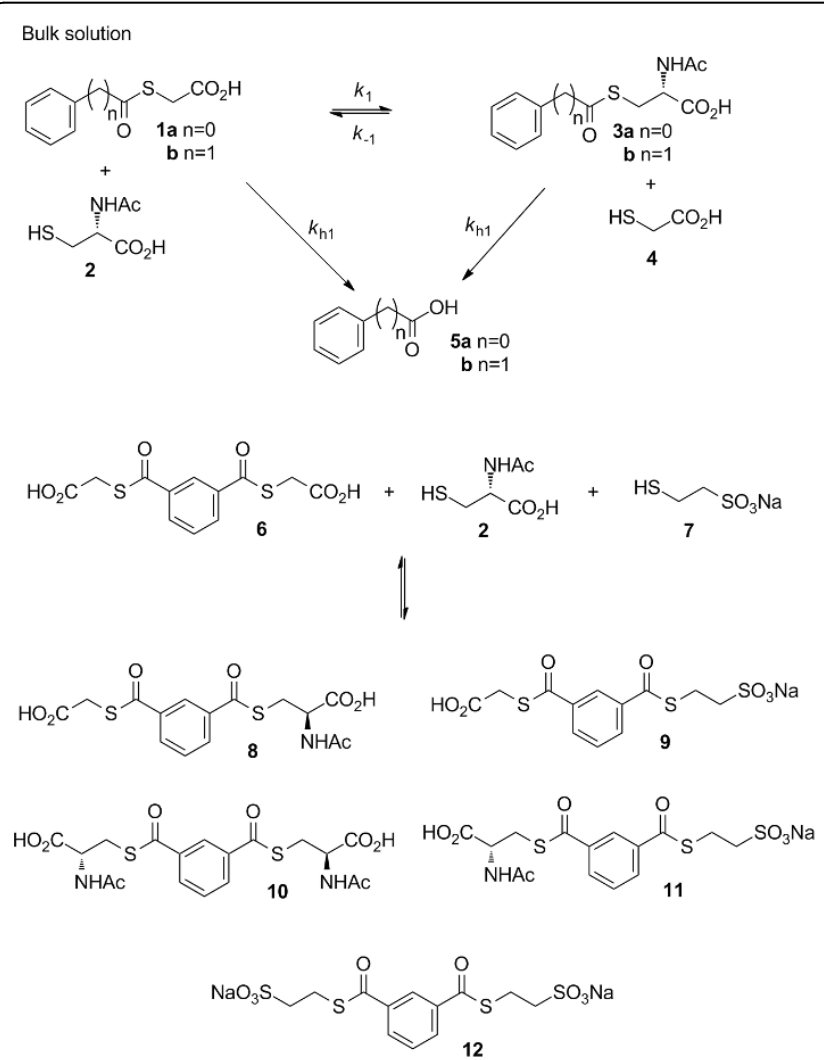

Egg PC bilayer interface
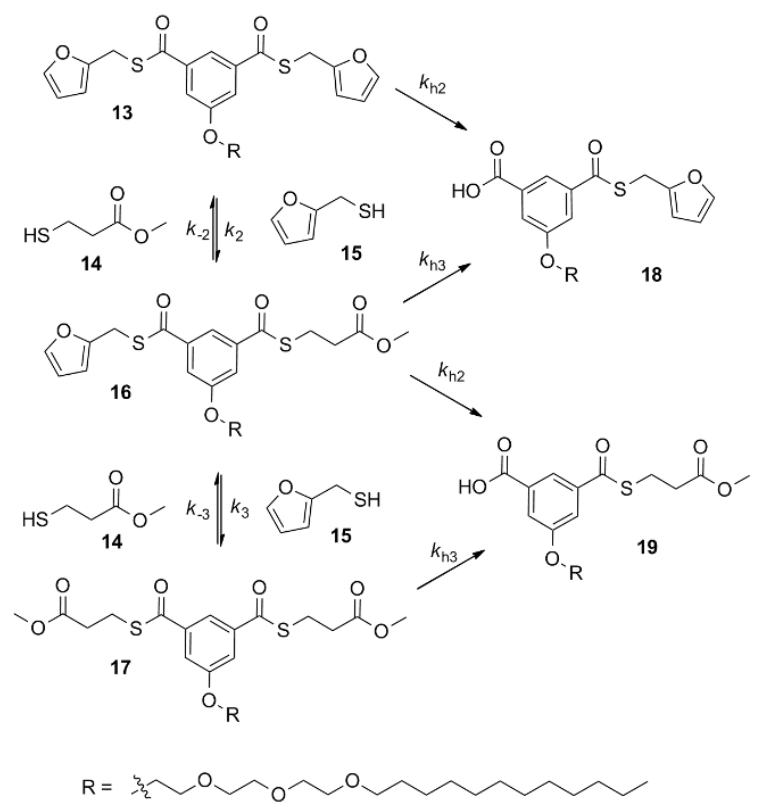

Figure 1 DCLs used for analysing the kinetics of thioester exchange and hydrolysis in bulk solution and at the lipid bilayer interface. 
10.06 [57]) in equimolar amounts and monitoring the formation of the thioester exchange product (3) and the hydrolysis product (5) using HPLC analysis. The amounts of the two products were determined from the peak areas in the HPLC traces, assuming that all thioesters have the same molar absorptivity. This data was plotted as a function of time and fitted using Dynafit software [58]. As both temperature and $\mathrm{pH}$ are known to have a strong influence on the kinetics of transthioesterification and hydrolysis of thioesters, these experiments were performed at three different temperatures $\left(20,30\right.$ and $\left.40^{\circ} \mathrm{C}\right)$ and two different $\mathrm{pHs}(7.0$ and 8.0). A comparison of the data shows that rates of thioester exchange are comparable for DCLs containing 1a (Figure $2 \mathrm{a}$ and $2 \mathrm{c}$ ) or $\mathbf{1 b}$ (Figure $2 \mathrm{~b}$ and $2 \mathrm{~d}$ ) when subjected to the same conditions, whereas hydrolysis of $\mathbf{1 b}$ proceeds significantly faster than that of benzoic acidderived thioester 1a. This observation is consistent with reports that aliphatic thioesters are prone to hydrolysis, particularly at higher $\mathrm{pH}[51,59,60]$. These plots also demonstrate that thioester exchange proceeds considerably faster with increased $\mathrm{pH}$. While DCLs at $\mathrm{pH} 7.0$ equilibrate in approximately 35 hours, at $\mathrm{pH} 8.0$ equilibrium is reached within 5 to 7 hours, depending on the structure of the building block.

The rate constants for thioester exchange obtained by fitting the data are in the range of $10^{-2} \mathrm{M}^{-1} \mathrm{~s}^{-1}$ (Table 1), which is about one order of magnitude lower than the corresponding rate constants determined for thioesters with aliphatic moieties at the acyl carbon $[61,62]$. Transthioesterification rates are comparable for $\mathbf{1 a}$ and $\mathbf{1 b}$ whereas hydrolysis is approximately 20 times faster in 1b. Surprisingly, hydrolysis becomes less competitive upon raising the $\mathrm{pH}$ from 7.0 to 8.0 as the rate of transthioesterification is increased 6-8-fold while the rate of hydrolysis merely doubles (Table 1). The temperaturedependence of the two competing processes, on the other hand, is comparable, so working at a higher temperature is a feasible method of achieving faster equilibration.

The experiments with the model thioesters $\mathbf{1 a}$ and $\mathbf{1 b}$ established that it is preferable to utilise building blocks with the acyl carbon directly attached to the aromatic core; including an aliphatic spacer leads to significant competition by hydrolysis. Therefore, in further experiments we focused on the former design.

Dynamic combinatorial chemistry relies on thermodynamic equilibrium being reached. In order to prove that this is indeed the case, we have performed experiments in which the same DCL is approached from two different starting points. For this purpose bis(thioester) 6 was synthesised (Figure 3) and a DCL containing this building block and the two thiols 2 and 7 was set up and equilibrated (Figure 1). The other starting point consisted of two libraries, one containing 6 and 2 , and the second containing 6 and 7 . Both of these libraries were allowed to equilibrate separately, then mixed and allowed to re-equilibrate. Comparable product distributions were obtained in both experiments (Figure 4), indicating that thermodynamic equilibrium is reached using the conditions established in the kinetic studies above.

The above results indicate that thioester exchange proceeds smoothly in bulk solution in the required timescale. Thus, the scene was set to perform similar experiments at the lipid bilayer interface.

\section{Thioester chemistry at the phospholipid bilayer interface} In order to study thioester chemistry at the phospholipid bilayer interface a derivative of $\mathbf{6}$ was prepared that was equipped with an alkyl chain for incorporation in lipid vesicles and a triethylene glycol spacer to facilitate access of thiols to the thioester functionality of the head group (13 in Figure 1). The synthetic route to this compound is shown in Figure 3. To set up phospholipid-based DCLs, large unilamellar vesicles

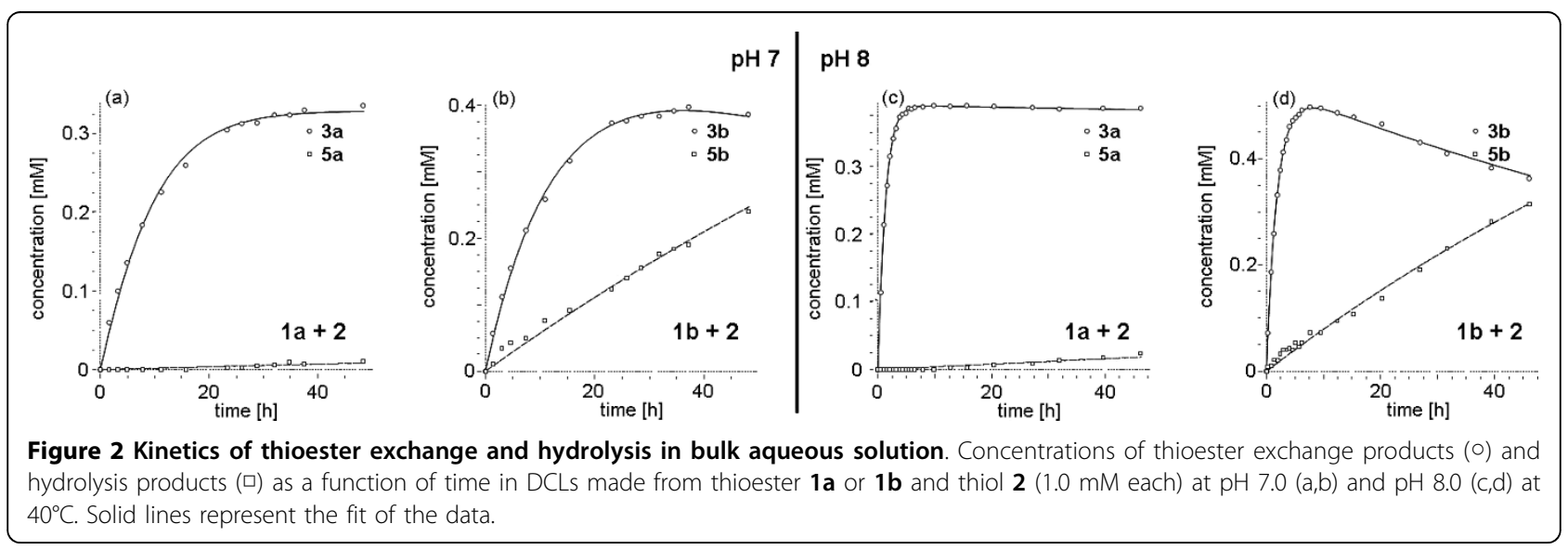


Table 1 Rate constants defined in Figure 1 for thioester exchange and hydrolysis at different temperatures and pHs

\begin{tabular}{|c|c|c|c|c|c|c|c|}
\hline starting material & $\mathrm{pH}$ & $\mathrm{T}\left[{ }^{\circ} \mathrm{C}\right]$ & $k_{1}\left[\mathrm{M}^{-1} \mathrm{~s}^{-1}\right]$ & $k_{-1}\left[\mathrm{M}^{-1} \mathrm{~s}^{-1}\right]$ & $k_{h 1}\left[\mathrm{~s}^{-1}\right]$ & $k_{1} / k_{-1}$ & $K^{[\mathrm{a}]}$ \\
\hline \multirow[t]{4}{*}{$1 \mathrm{a}$} & 7.0 & 40 & $0.868 \times 10^{-2} \pm 1.8 \times 10^{-4}$ & $3.51 \times 10^{-2} \pm 1.3 \times 10^{-3}$ & $5 \times 10^{-5} \pm 2 \times 10^{-5}$ & 0.25 & 0.29 \\
\hline & 8.0 & 40 & $7.58 \times 10^{-2} \pm 6.8 \times 10^{-3}$ & $18.5 \times 10^{-2} \pm 2.3 \times 10^{-2}$ & $1.1 \times 10^{-4} \pm 1 \times 10^{-5}$ & 0.41 & 0.43 \\
\hline & & 30 & $2.93 \times 10^{-2} \pm 3 \times 10^{-4}$ & $6.42 \times 10^{-2} \pm 1.1 \times 10^{-3}$ & $6 \times 10^{-5} \pm 1 \times 10^{-5}$ & 0.46 & 0.46 \\
\hline & & 20 & $1.22 \times 10^{-2} \pm 1 \times 10^{-4}$ & $2.92 \times 10^{-2} \pm 4 \times 10^{-4}$ & $2 \times 10^{-5} 1 \times 10^{-5}$ & 0.42 & 0.44 \\
\hline \multirow[t]{4}{*}{$1 b$} & 7.0 & 40 & $1.08 \times 10^{-2} \pm 2 \times 10^{-4}$ & $1.00 \times 10^{-2} \pm 8 \times 10^{-4}$ & $1.64 \times 10^{-3} \pm 3 \times 10^{-5}$ & 1.08 & 1.10 \\
\hline & 8.0 & 40 & $8.13 \times 10^{-2} \pm 1.4 \times 10^{-3}$ & $6.12 \times 10^{-2} \pm 2.1 \times 10^{-3}$ & $2.29 \times 10^{-3} \pm 3 \times 10^{-5}$ & 1.33 & 1.28 \\
\hline & & 30 & $4.09 \times 10^{-2} \pm 1.2 \times 10^{-3}$ & $4.01 \times 10^{-2} \pm 2.1 \times 10^{-3}$ & $8.0 \times 10^{-4} \pm 4 \times 10^{-5}$ & 1.02 & 1.08 \\
\hline & & 20 & $1.54 \times 10^{-2} \pm 2 \times 10^{-4}$ & $1.69 \times 10^{-2} \pm 6 \times 10^{-4}$ & $3.2 \times 10^{-4} \pm 2 \times 10^{-5}$ & 0.91 & 0.92 \\
\hline
\end{tabular}

${ }^{a}$ Determined from the concentrations of thiol and thioesters observed in the equilibrated libraries.

(200 nm diameter) were prepared in phosphate buffer $\mathrm{pH} 8.0$ by mixing egg phosphatidylcholine (egg PC) with $10 \mathrm{~mol} \% \mathrm{13}$, followed by extrusion through a polycarbonate membrane. Different thiols were then added to the resulting solutions.

Where finding suitable analytical conditions for studying DCLs in bulk solution was straightforward, identification of products in DCLs in the presence of phospholipids was considerably more challenging. Even though, lacking a chromophore, lipids do not interfere with the UV/Vis detection of compounds, they complicate the MS analysis significantly. In initial attempts we found that egg PC is not eluted completely from the column under the conditions used for analysis and leaches slowly with every gradient chromatography performed. The resulting broad MS signal of the phospholipids concealed those of any other species present in the DCLs, hampering the identification of thioester exchange products. After exploring several different approaches, the best method for removing the egg PC from the column was found to be washing with THF containing triethylamine and trifluoroacetic acid at regular intervals, usually after five to ten chromatography runs had been performed. In combination with using very low injection volumes for LC-MS analysis, these measures proved suitable for achieving MS traces that allowed the assignment of library members in a DCL containing egg PC.

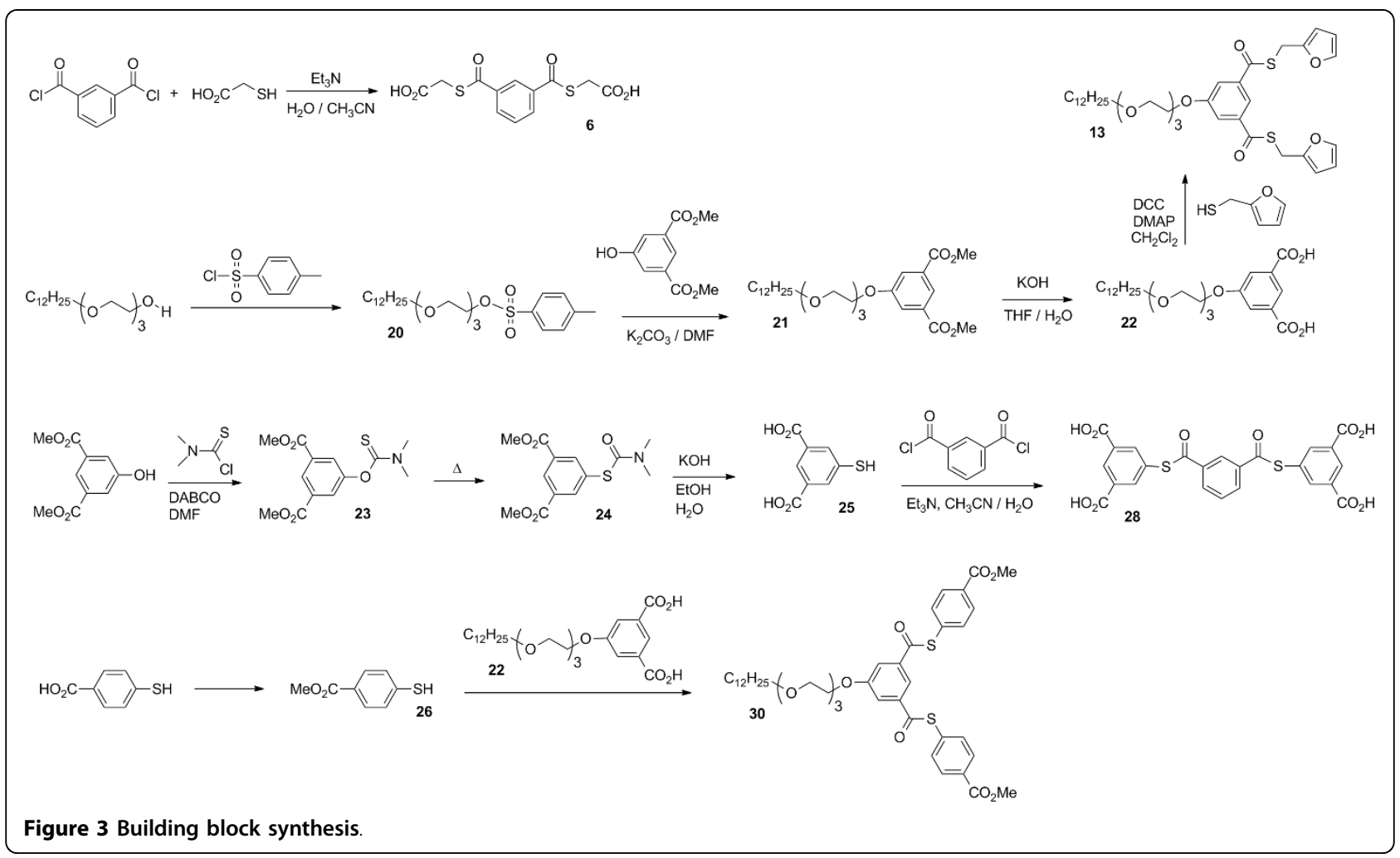




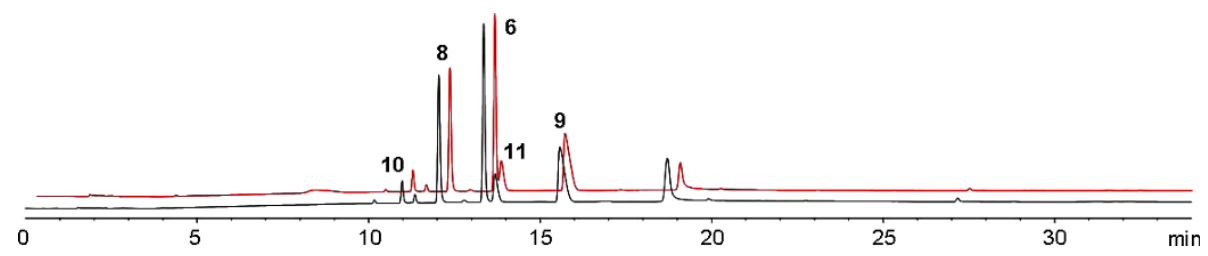

Figure 4 Evidence for equilibration in bulk solution. HPLC analysis of two DCLs reaching the same distribution from two different starting points. Black: $1.0 \mathrm{mM} \mathbf{6}, 1.0 \mathrm{mM} \mathbf{2}$ and $1.0 \mathrm{mM} \mathbf{7}$ mixed and equilibrated. Red: $1.0 \mathrm{mM} \mathbf{6}$ and $2.0 \mathrm{mM} \mathbf{2}$ equilibrated separately from $1.0 \mathrm{mM} \mathbf{6}$ and $2.0 \mathrm{mM} \mathbf{7}$, then mixed and re-equilibrated.

The kinetic analysis of thioester exchange for a mixture of bis(thioester) 13 with thiol 14 (Figure 1; $K_{\mathrm{a}}$ 9.33 [61]) at the lipid bilayer was carried out using the optimised conditions for this type of thioester building block of $\mathrm{pH} 8.0$ and a temperature of $40^{\circ} \mathrm{C}$. As $\mathbf{1 3}$ has two thioester moieties, the accumulation of two thioester exchange products and two hydrolysis products was recorded over time and the data fitted using Dynafit software (Figure 1 and Figure 5). The extinction coefficients of thioester starting material and thioester exchange products were assumed to be the same. Although furan exhibits a low level of absorbance at 260 $\mathrm{nm}$, it is negligible in comparison with that of the aromatic ring system. Thioester exchange at the lipid bilayer proceeds somewhat slower than in solution under the same conditions, presumably due to a combination of structural differences of the reacting molecules and a lower polarity of the microenvironment of the lipid bilayer [61-63] in comparison with bulk solution. However, equilibrium is reached within 24 hours and Table 2 shows that the rate constants are in the same order of magnitude at the lipid bilayer and in solution (cf. second row in Table 1), making this system suitable

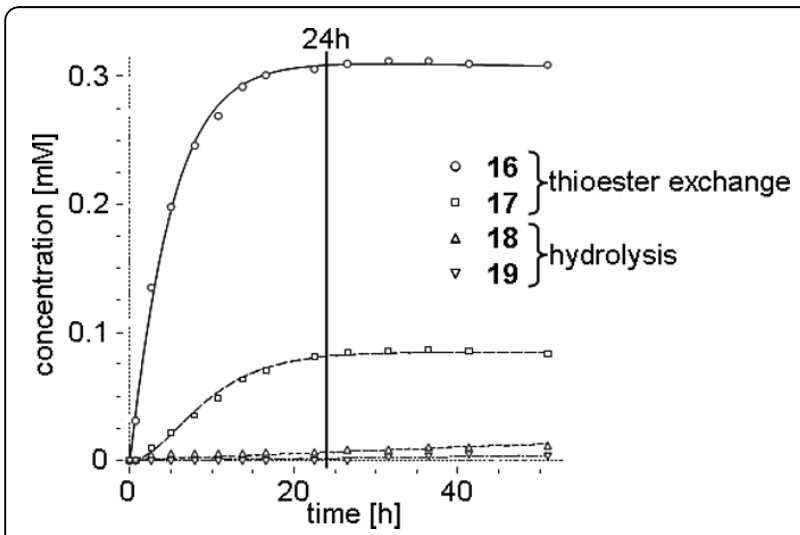

Figure 5 Thioester exchange and hydrolysis at the lipid bilayer interface. Formation of thioester exchange products $16(0)$ and 17 () and hydrolysis products $\mathbf{1 8}(\Delta)$ and $\mathbf{1 9}(\nabla)$ in a $\mathrm{DCL}$ made from 13 and $\mathbf{1 4}\left(1.0 \mathrm{mM}\right.$ each) at the lipid bilayer at $\mathrm{pH} 8.0$ at $40^{\circ} \mathrm{C}$. Solid lines represent the fit of the data. for studying dynamic combinatorial chemistry at the lipid bilayer.

In order to show that equilibrium is also reached at the lipid bilayer, experiments were carried out analogous to those performed in solution, but now starting from thioester 13. The two thiols used in this case are $4\left(\mathrm{p} K_{\mathrm{a}}\right.$ 10.06 [57]) and 7 ( $\mathrm{p} K_{\mathrm{a}} 9.53$ [57]), and the two HPLC traces of the DCLs obtained from different starting points are again in excellent agreement (Figure 6). Libraries were allowed to equilibrate for 24 hours. Interestingly, the equilibrium distribution strongly favours the less polar starting material, with only small amounts of the mono-exchange products present, despite the large excess of both thiols 4 and 7. These global concentrations are, however, unlikely to be reflected by the local concentrations of the thiols in the vicinity of the lipid bilayer interface where thioester exchange is taking place. The microenvironment created by the lipids is considerably less polar than bulk solution [63-65], thus disfavouring the recruitment of more polar species such as negatively charged $\mathbf{4}$ and $\mathbf{7}$ to the lipid bilayer interface, presumably due to costly desolvation.

We also probed whether the thiol building blocks are able to cross the bilayer membrane and/or the membrane-bound thioesters are able to undergo flip-flop. Experiments were performed in which thiols were added after vesicle formation (single-sided addition) or where vesicles were prepared in the presence of thiol (double-sided addition). If the membrane permeation of the thiols through the bilayer and thioester flip-flop are both slow on the timescale of the experiment, single-sided and double-sided addition would result in different DCL compositions. For single-sided addition only the fraction of thioester building block present in the outer leaflet of the lipid bilayer would be exposed to the thiols and therefore be able to participate in transthioesterification. The HPLC analysis of two DCLs where thiols were added prior to, or after vesicle formation show comparable product distributions (see Additional file 1, Figure S1), indicating that diffusion of thiols across the lipid bilayer and/or flip-flop of the uncharged thioester $\mathbf{1 3}$ are fast on the timescale of the experiment. 
Table 2 Rate constants as defined in Figure 1 for thioester exchange and hydrolysis at the lipid bilayer interface in a DCL made from 13 and 14 at pH 8.0 and $40^{\circ} \mathrm{C}$

\begin{tabular}{ccccccc}
\hline starting material & $\boldsymbol{k}_{\mathbf{2}}\left[\mathrm{M}^{-1} \mathbf{s}^{-1}\right]$ & $\boldsymbol{k}_{-\mathbf{2}}\left[\mathrm{M}^{-1} \mathbf{s}^{-1}\right]$ & $\boldsymbol{k}_{\mathbf{3}}\left[\mathrm{M}^{-1} \mathbf{s}^{-1}\right]$ & $\boldsymbol{k}_{-\mathbf{3}}\left[\mathrm{M}^{-1} \mathbf{s}^{-1}\right]$ & $\boldsymbol{k}_{\boldsymbol{h} 2}\left[\mathbf{s}^{-1}\right]$ & $\boldsymbol{k}_{\boldsymbol{h} 3}\left[\mathbf{s}^{-1}\right]$ \\
\hline $\mathbf{1 3}$ & $1.65 \times 10^{-2}$ & $3.31 \times 10^{-2}$ & $1.32 \times 10^{-2}$ & $5.07 \times 10^{-2}$ & $0.008 \times 10^{-2}$ & $0.004 \times 10^{-2}$ \\
& $\pm 0.2 \times 10^{-3}$ & $\pm 0.8 \times 10^{-3}$ & $\pm 0.5 \times 10^{-3}$ & $\pm 2.7 \times 10^{-3}$ & $\pm 0.9 \times 10^{-5}$ & $\pm 0.6 \times 10^{-4}$ \\
\hline
\end{tabular}

Comparing DCL distributions at the bilayer interface with those in bulk solution

With reaction conditions established for solution-phase as well as vesicle interface-based thioester exchange chemistry, we proceeded to increase the complexity of the DCLs by using dithiols and comparing the resulting product distribution in solution with that at the lipid bilayer. We explored the use of both aromatic and aliphatic dithiols. Larsson et al.[49] pointed out that in thioester DCLs that contain both types of thiols the equilibrium strongly favours aliphatic thioester and free aromatic thiols due to the significant differences in $\mathrm{p} K_{\mathrm{a}} \mathrm{s}$ between aliphatic and aromatic thiols. Given this poor compatibility between these two classes of thiols, DCLs containing building blocks 6 and 13 were mixed with aliphatic dithiol 27 (Figure 7). In order to also explore aromatic thiols we have prepared thioesters $\mathbf{2 8}$ and $\mathbf{3 0}$ (see Figure 3 for the synthetic routes), which were mixed with aromatic dithiol 29 (Figure 7).

The HPLC traces of the libraries with aliphatic thiols are shown in Figure 8, with Figure 8a showing the DCL in bulk water with 6 and 27, and Figure 8b showing the DCL made from 13 and 27 in the presence of egg PC. The product distributions in both libraries are completely different. In solution the cyclic heterodimer dominates and a small amount of the cyclic tetramer is also observed. At the lipid bilayer only a very small amount of a cyclic species is formed and the mixture is dominated by starting material $\mathbf{1 3}$ and to a lesser extent linear thioesters.

Similarly, the libraries containing aromatic thiols also show significant differences in the species that are formed in bulk water and at the lipid bilayer (Figure 9). In bulk water no compounds can be detected that contain more than one unit of thioester building block 28. Significant amounts of disulfide and hydrolysis side products are formed. At the lipid bilayer many different linear species are present containing multiple copies of thioester $\mathbf{3 0}$ (the membrane-bound analogue of 28), with 13 being the major species. Note that the relative HPLC peak areas do not reflect relative concentrations when the library members exhibit different molar absorptivities.

Although it was pointed out in the previous section that less polar thiol building blocks may favour the thioester exchange species rather than the starting material, the poor water-solubility of more hydrophobic building blocks prohibited their use in this study.

The differences in product distribution in bulk water and at the lipid bilayer observed for both aliphatic and aromatic thiol-thioester systems studied here can be attributed to differences in local concentration. Libraries at the lipid bilayer interface are biased towards species that are rich in the membrane-bound amphiphilic building block 13 which is probably caused by a local concentrating effect of the lipid vesicles.

\section{Conclusions}

Our results show that it is possible to use dynamic combinatorial chemistry based on reversible thioester chemistry at the phospholipid bilayer interface and achieve equilibration within 24 hours at $\mathrm{pH} 7.0$ or 8.0 at millimolar building block concentrations. Conditions for LCMS analysis of the libraries of molecules bound to the egg PC membranes have been developed. Kinetic

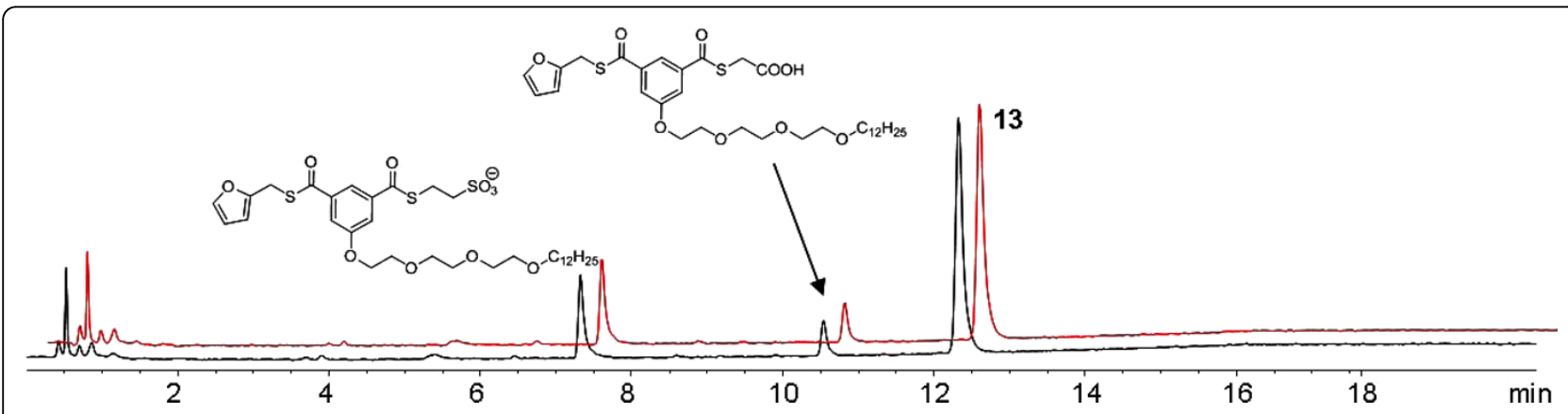

Figure 6 Evidence for equilibration at the phospholipid bilayer interface. HPLC analysis of two DCLs reaching the same equilibrium distribution from two different starting points. Black: 10 mM egg PC, 1.0 mM 13, 10 mM 4 and 10 mM 7 mixed and equilibrated. Red: 10 mM egg PC, 1.0 mM 13 and 20 mM 4 equilibrated separately from 10 mM egg PC, 1.0 mM 13 and 20 mM 7, then mixed and equilibrated. 


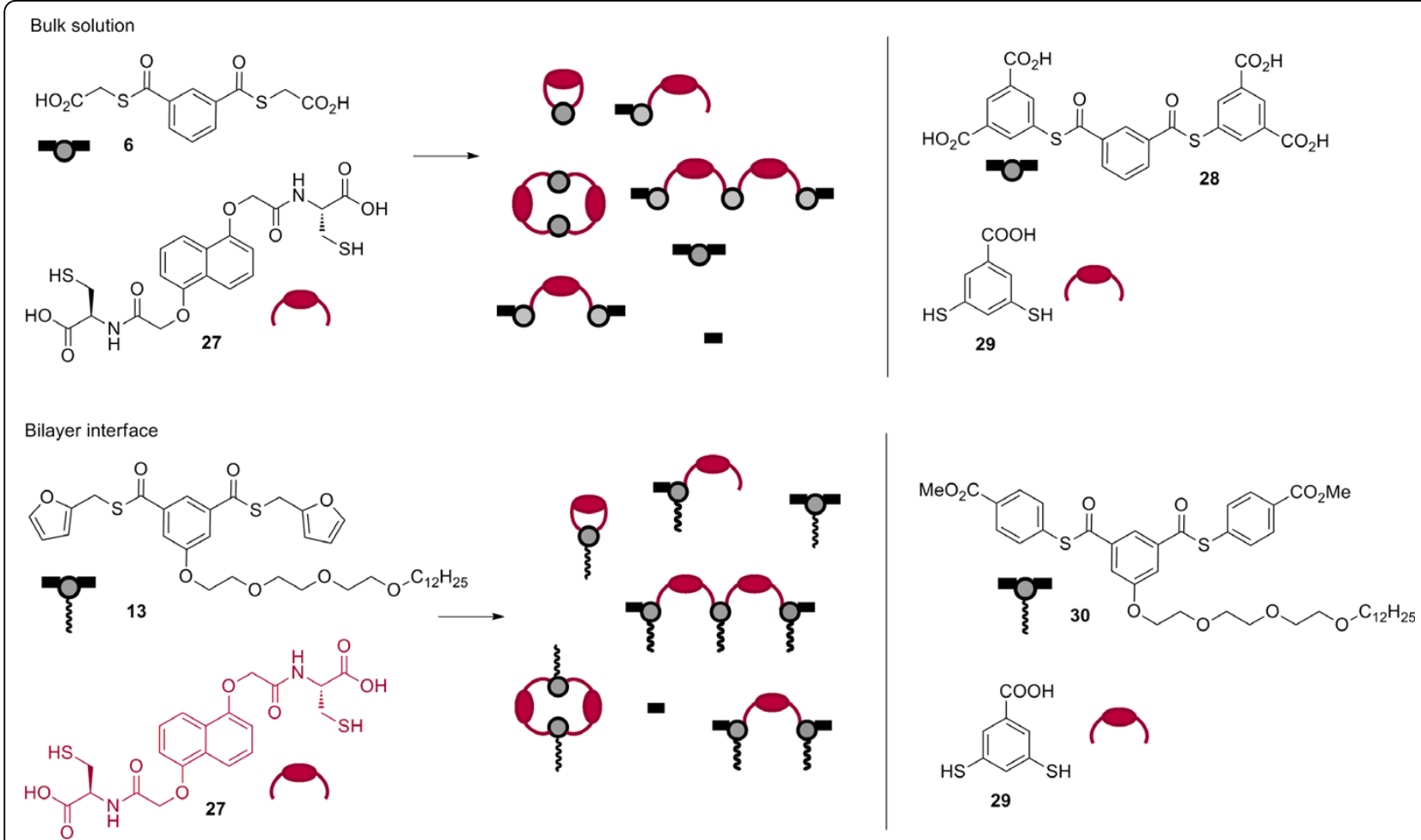

Figure 7 Thioester DCLs featuring aliphatic (left) and aromatic (right) dithiols in bulk aqueous solution (top) and at the phospholipid bilayer interface (bottom).

investigations revealed that thioester hydrolysis is not competitive with thioester exchange, provided that thioesters are used that are derived from aromatic carboxylic acids. Perhaps counterintuitively, hydrolysis is less competitive at the higher $\mathrm{pH}$, because the rate of hydrolysis increases less rapidly with increasing $\mathrm{pH}$ than the rate of exchange.

DCLs at the membrane interface facilitate access to library members featuring multiple copies of membrane- bound building blocks. Thus, at the membrane interface the composition of the DCLs is biased towards larger linear species, while smaller macrocyclic species are more abundant in solution-phase libraries. We attribute this difference to the confinement of the building blocks to two dimensions at the bilayer interface. This confinement leads to a high local concentration of the membrane-bound building blocks, shifting the ring-chain equilibrium in favour of chain-like compounds. These
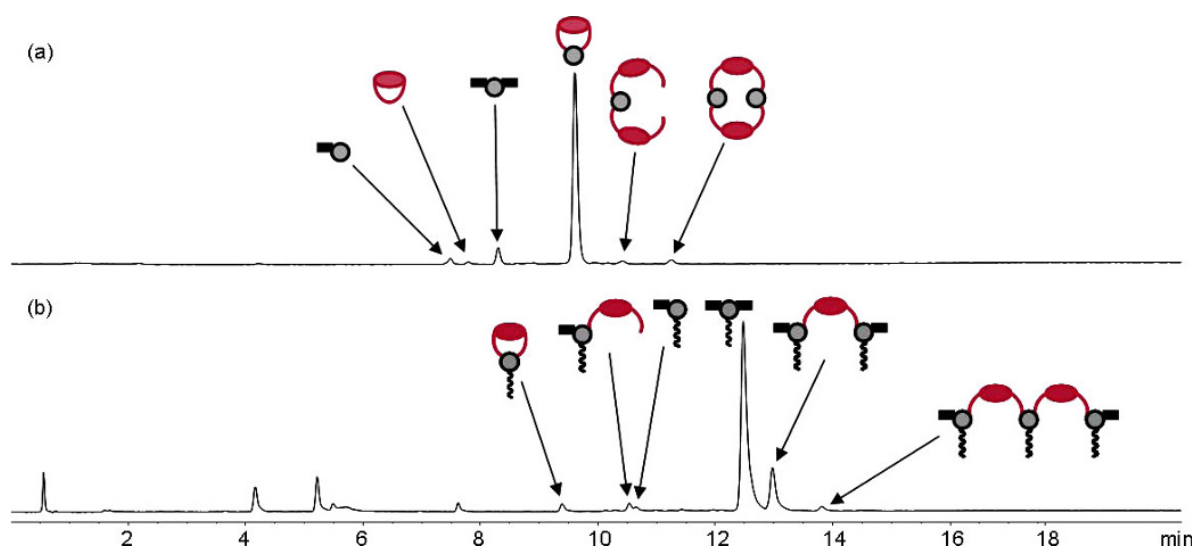

Figure 8 Comparing the compositions of DCLs with aliphatic dithiols in bulk aqueous solution with that at the lipid bilayer interface HPLC analyses of DCLs containing (a) $1.0 \mathrm{mM} \mathbf{6}$ and $1.0 \mathrm{mM} \mathbf{2 7}$ or (b) $10 \mathrm{mM}$ egg PC, $1.0 \mathrm{mM} 13$ and $1.0 \mathrm{mM} \mathbf{2 7}$. 

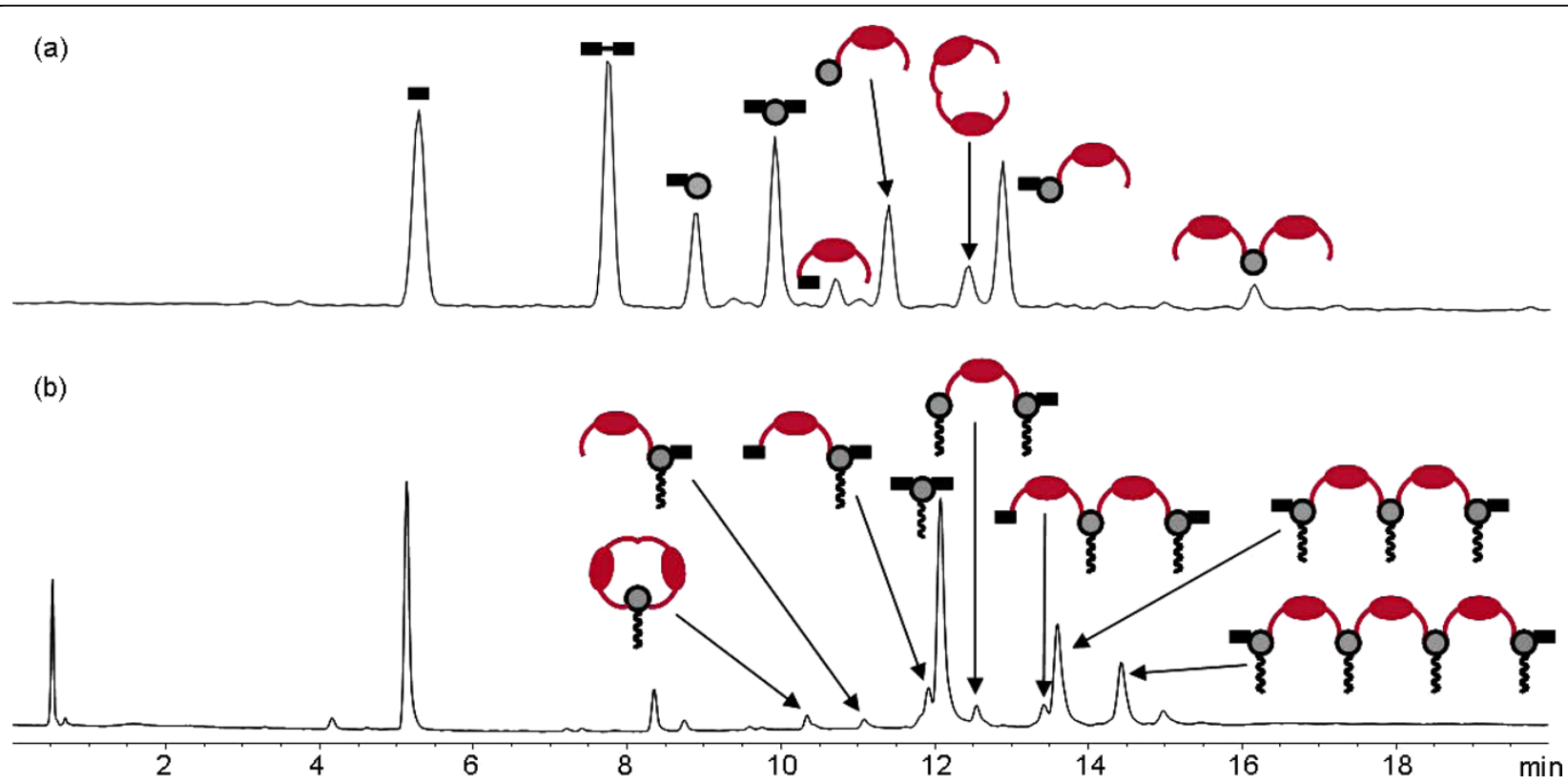

Figure 9 Comparing the compositions of DCLs with aromatic dithiols in bulk aqueous solution with that at the lipid bilayer interface HPLC analyses of DCLs containing (a) $1.0 \mathrm{mM} 28$ and $1.0 \mathrm{mM} \mathbf{2 9}$ or (b) $10 \mathrm{mM}$ egg PC, $1.0 \mathrm{mM} \mathbf{3 0}$ and $1.0 \mathrm{mM} \mathbf{2 9}$.

results imply that interfaces may be used as a platform to direct systems to the formation of (informational) polymers under conditions where small macrocycles would dominate in the absence of interfacial confinement.

\section{Experimental \\ Materials}

Chemicals were purchased from Aldrich, Acros, Alfa Aesar, Avocado Organics, Fluka, or Lancaster Synthesis and used without further purification. Solvents used in synthesis were distilled prior to use and anhydrous solvents were distilled from a drying agent under argon. LC-MS grade solvents (acetonitrile, water, formic acid and trifluoroacetic acid) were obtained from Romil and used without further purification. Thin layer chromatography was carried out on glass or aluminium plates coated with silica gel 60 F254 (Merck). Column chromatography was performed on silica gel $(0.040-0.063 \mathrm{~mm})$ purchased from Breckland Scientific Systems. Silica gel (0.015-0.040 mm) from Merck was used for dry column vacuum chromatography. Dithiols 27 [66] and 29 [67] have been prepared following literature procedures.

\section{2-(Benzoylthio)acetic acid 1a}

Benzoic acid (10 mmol, $1.22 \mathrm{~g})$ was dissolved in anhydrous $\mathrm{CH}_{2} \mathrm{Cl}_{2}(20 \mathrm{~mL})$. Oxalylchloride $(12 \mathrm{mmol}, 1.02$ $\mathrm{mL}$ ) was added and the solution was stirred at room temperature overnight under a $\mathrm{N}_{2}$ atmosphere. The solvent was evaporated in vacuo and the resulting acid chloride was used for the next step without further purification.

To a stirred solution of mercaptoacetic acid (1.87 $\mathrm{mmol}, 0.13 \mathrm{~mL})$ and triethylamine $(3.82 \mathrm{mmol}, 0.53$ $\mathrm{mL})$ in a $1: 1$ mixture of water and acetonitrile $(10 \mathrm{~mL})$, the acid chloride $(2.01 \mathrm{mmol}, 0.31 \mathrm{~g})$ was added. After 4 hours the mixture was washed three times with hexane. The aqueous phase was acidified and extracted three times with $\mathrm{CH}_{2} \mathrm{Cl}_{2}$. The combined organic phases were dried over sodium sulphate, filtered and the solvent was evaporated. Column chromatography (silica, DCM/acetone/formic acid 96:4:0.5) yielded $1.37 \mathrm{~g}$ (71\% over two steps) of a white solid. Characterisation matched that described in ref. [68].

\section{2-(2-Phenylacetylthio)acetic acid 1b}

Prepared analogous to the procedure for the synthesis of 1a. Yield: $1.32 \mathrm{~g}$ (63\% over two steps) of an oil that crystallized upon scratching. ${ }^{1} \mathrm{H}-\mathrm{NMR}\left(\mathrm{CDCl}_{3}, 400 \mathrm{MHz}\right)$ : $\delta=7.37-7.27(\mathrm{~m}, 5 \mathrm{H}, \mathrm{a}-\mathrm{c}), 3.89(\mathrm{~s}, 2 \mathrm{H}, \mathrm{e}), 3.70(\mathrm{~s}, 2$ $\mathrm{H}, \mathrm{d}) .{ }^{13} \mathrm{C}$-NMR $\left(\mathrm{CDCl}_{3}, 400 \mathrm{MHz}\right): \delta=195.8,173.9$, 132.7, 129.7, 128.8, 127.7, 49.9, 31.3. Exact mass calculated: 209.0278, found: $209.0277\left[\mathrm{M}-\mathrm{H}^{+}\right]$. Melting point: $90-92^{\circ} \mathrm{C}$.

\section{S,S-Diacetic acid benzene-1,3-bis(carbothioate) 6}

Mercaptoacetic acid $(2.02 \mathrm{mmol}, 0.14 \mathrm{~mL})$ and triethylamine $(3.97 \mathrm{mmol}, 0.55 \mathrm{~mL})$ were dissolved in a $1: 1 \mathrm{mix}-$ ture of water and acetonitrile $(10 \mathrm{~mL})$. After addition of isophthaloyl dichloride $(0.99 \mathrm{mmol}, 0.20 \mathrm{~g})$ the solution 
was stirred at room temperature for 5 hours. The mixture was washed with hexane three times and then lyophilised. The residue was redissolved in water and the product precipitated by acidifying with $3 \mathrm{~N} \mathrm{HCl}$. Recrystallisation from methanol yielded a white powder (33 $\mathrm{mg}, 11 \%)$.

${ }^{1} \mathrm{H}-\mathrm{NMR}\left(\mathrm{CD}_{3} \mathrm{OD}, 400 \mathrm{MHz}\right): \delta=8.49\left(\mathrm{t}, 1 \mathrm{H},{ }^{4} \mathrm{~J}=\right.$ 1.5, d), $8.23\left(\mathrm{dd}, 2 \mathrm{H},{ }^{4} \mathrm{~J}=1.7,{ }^{3} \mathrm{~J}=7.8, \mathrm{e}\right), 7.69(\mathrm{t}, 1 \mathrm{H}$, $\mathrm{J}=7.8, \mathrm{f}), 3.94(\mathrm{~s}, 4 \mathrm{H}, \mathrm{b}) .{ }^{13} \mathrm{C}-\mathrm{NMR}\left(\mathrm{CD}_{3} \mathrm{OD}\right.$, $400 \mathrm{MHz}): \delta=190.9,171.9,138.3,133.1,131.0,126.5$, 32.3. Exact mass calculated: 336.9817 , found: 336.9825 $\left[\mathrm{M}+\mathrm{Na}^{+}\right]$. Melting point: $199-201^{\circ} \mathrm{C}$.

\section{2-(2-(2-(Dodecyloxy)ethoxy)ethoxy)ethyl 4-methylbenzenesulfonate 20}

Anhydrous pyridine (10.01 mmol, $0.81 \mathrm{~mL}$ ) was added to a solution of triethyleneglycol monododecyl ether (2.01 mmol, $0.69 \mathrm{~mL})$ in anhydrous $\mathrm{CH}_{2} \mathrm{Cl}_{2}(20 \mathrm{~mL})$ stirring at $0^{\circ} \mathrm{C}$ under a $\mathrm{N}_{2}$ atmosphere. After 10 minutes $p$-toluenesulfonyl chloride (4.98 mmol, $0.95 \mathrm{~g})$ was added. The solution was allowed to warm up slowly to room temperature and left to stir for a further 2 days before washing it with $3 \mathrm{~N} \mathrm{HCl}$, saturated sodium bicarbonate solution and brine. The organic layer was dried over sodium sulfate and filtered. After the solvent had been evaporated the residue was purified using dry column vacuum chromatography $(0-35 \%$ EtOAc in hexane $(\mathrm{v} / \mathrm{v})$ in $2.5 \%$ increments $)$ to yield a clear oil $(0.69 \mathrm{~g}$, $73 \%)$.

${ }^{1} \mathrm{H}-\mathrm{NMR}\left(\mathrm{CDCl}_{3}, 400 \mathrm{MHz}\right): \delta=7.77(\mathrm{~d}, 2 \mathrm{H}, \mathrm{J}=8.3$, c), $7.31(\mathrm{~d}, 2 \mathrm{H}, \mathrm{J}=8.4, \mathrm{~b}), 4.13(\mathrm{t}, 2 \mathrm{H}, \mathrm{J}=4.7, \mathrm{~d}), 3.66$ $(\mathrm{t}, 2 \mathrm{H}, \mathrm{J}=4.7$, e) $3.59-3.51(\mathrm{~m}, 8 \mathrm{H}), 3.41(\mathrm{t}, 2 \mathrm{H}, \mathrm{J}=$ 6.9, g), 2.42 (s, $3 \mathrm{H}, \mathrm{a}), 1.56(\mathrm{~m}, 2 \mathrm{H}, \mathrm{h}), 1.29-1.23(\mathrm{~m}$, $18 \mathrm{H}, \mathrm{i}), 0.85(\mathrm{t}, 3 \mathrm{H}, \mathrm{j}) .{ }^{13} \mathrm{C}-\mathrm{NMR}\left(\mathrm{CDCl}_{3}, 400 \mathrm{MHz}\right)$ : $\delta=144.6,133.0,129.7,127.9,71.4,70.7,70.6,70.4,69.9$, 69.1., 68.6, 31.8, 29.6 - 29.4, 29.4, 29.2, 26.0, 22.6, 21.5, 14.0. Exact mass calculated: 473.2937 , found: 473.2949 $\left[\mathrm{M}+\mathrm{H}^{+}\right]$.

\section{Dimethyl 5-(2-(2-(2-(dodecyloxy)ethoxy)ethoxy)ethoxy) isophthalate 21}

2-(2-(2-(Dodecyloxy)ethoxy)ethoxy)ethyl 4-methylbenzenesulfonate $(20 ; 4.99 \mathrm{mmol}, 2.36 \mathrm{~g})$ and dimethyl-5hydroxyisophthalic acid $(5.00 \mathrm{mmol}, 1.05 \mathrm{~g})$ were dissolved in anhydrous DMF $(100 \mathrm{~mL})$ and potassium carbonate (19.97 mmol, $2.76 \mathrm{~g}$ ) was added. The mixture was stirred at $100^{\circ} \mathrm{C}$ for 4 hours. After cooling down, $\mathrm{CH}_{2} \mathrm{Cl}_{2}(100 \mathrm{~mL})$ was added and the mixture was stirred for 10 minutes at room temperature, then washed with $3 \mathrm{~N} \mathrm{HCl}$ and brine, dried over sodium sulfate and filtered. The solvent was evaporated to yield $2.23 \mathrm{~g}$ (87\%) of a clear oil.

${ }^{1} \mathrm{H}-\mathrm{NMR}\left(\mathrm{CDCl}_{3}, 400 \mathrm{MHz}\right): \delta=8.27(\mathrm{t}, 1 \mathrm{H}, \mathrm{J}=1.5$, b), $7.77(\mathrm{~d}, 2 \mathrm{H}, \mathrm{J}=1.5, \mathrm{c}), 4.21(\mathrm{t}, 2 \mathrm{H}, \mathrm{J}=4.8, \mathrm{~d}), 3.93$ (s, $6 \mathrm{H}, \mathrm{a}), 3.89(\mathrm{t}, 2 \mathrm{H}, \mathrm{J}=4.8, \mathrm{e}), 3.75-3.56(\mathrm{~m}, 8 \mathrm{H}$, f), $3.44(\mathrm{t}, 2 \mathrm{H}, \mathrm{J}=6.9, \mathrm{~g}), 1.56(\mathrm{~m}, 2 \mathrm{H}, \mathrm{h}), 1.31-1.25$ $(\mathrm{m}, 18 \mathrm{H}, \mathrm{i}), 0.87(\mathrm{t}, 3 \mathrm{H}, \mathrm{j}) .{ }^{13} \mathrm{C}-\mathrm{NMR}\left(\mathrm{CDCl}_{3}, 400\right.$ $\mathrm{MHz}): \delta=166.1,158.9,131.8,123.1,120.0,71.6,70.9$, 70.7, 70.7, 70.1, 69.5, 68.1, 52.4, 31.9, 29.7 - 29.6, 29.5, 29.3, 26.1, 22.7, 14.1. Exact mass calculated: 511.3271, found: $511.3292\left[\mathrm{M}+\mathrm{H}^{+}\right]$.

\section{5-(2-(2-(2-(Dodecyloxy)ethoxy)ethoxy)ethoxy)isophthalic} acid 22

Dimethyl 5-(2-(2-(2-(dodecyloxy)ethoxy)ethoxy)ethoxy) isophthalate $(21 ; 4.36 \mathrm{mmol}, 2.20 \mathrm{~g})$ was dissolved in THF $(60 \mathrm{~mL}) .1 \mathrm{M} \mathrm{KOH}(20 \mathrm{~mL})$ was added and the solution was stirred for 15 hours. The THF was evaporated and the remaining aqueous solution was acidified and extracted with $\mathrm{CH}_{2} \mathrm{Cl}_{2}$ three times. The organic phase was washed with $3 \mathrm{~N} \mathrm{HCl}$ and brine, dried over sodium sulfate. Evaporation of solvent gave $2.06 \mathrm{~g}$ (98\%) of an off-white solid.

${ }^{1} \mathrm{H}-\mathrm{NMR}\left(\mathrm{CDCl}_{3}, 400 \mathrm{MHz}\right): \delta=8.02(\mathrm{t}, 1 \mathrm{H}, \mathrm{J}=1.2$, a), $7.58(\mathrm{~d}, 2 \mathrm{H}, \mathrm{J}=1.1, \mathrm{~b}), 4.15(\mathrm{t}, 2 \mathrm{H}, \mathrm{J}=4.2, \mathrm{c}), 3.92$ $(\mathrm{t}, 2 \mathrm{H}, \mathrm{J}=4.0, \mathrm{~d}), 3.86-3.63(\mathrm{~m}, 8 \mathrm{H}, \mathrm{e}), 3.45(\mathrm{t}, 2 \mathrm{H}, \mathrm{J}$ = 6.8, f), $1.56(\mathrm{~m}, 2 \mathrm{H}, \mathrm{g}), 1.30-1.21(\mathrm{~m}, 18 \mathrm{H}, \mathrm{h}), 0.86$ $(\mathrm{t}, 3 \mathrm{H}, \mathrm{i}) .{ }^{13} \mathrm{C}-\mathrm{NMR}\left(\mathrm{CDCl}_{3}, 400 \mathrm{MHz}\right): \delta=169.2$, $158.5,130.9,123.8,120.1,71.6,70.7,70.5,70.4,69.9$, 69.6, 67.7, 31.9, 29.7 - 29.6, 29.5, 29.5, 29.3, 26.0, 22.7, 14.1. Exact mass calculated: 483.2958 , found: 483.2968 $\left[\mathrm{M}+\mathrm{H}^{+}\right]$. Melting point: $80-82^{\circ} \mathrm{C}$.

\section{S,S-Bis(furan-2-ylmethyl) 5-(2-(2-(2-(dodecyloxy)ethoxy) ethoxy)ethoxy)benzene-1,3-bis(carbothioate) 13} 5-(2-(2-(2-(Dodecyloxy)ethoxy)ethoxy)ethoxy)isophthalic acid (22; $0.40 \mathrm{mmol}, 193 \mathrm{mg}), 2$-furanmethanethiol (0.99 mmol, $0.1 \mathrm{~mL})$ and DMAP $(0.10 \mathrm{mmol}, 12 \mathrm{mg})$ were dissolved in anhydrous $\mathrm{CH}_{2} \mathrm{Cl}_{2}(10 \mathrm{~mL})$ and cooled to $4^{\circ} \mathrm{C}$ on an ice bath. Dicyclohexylcarbodiimide $(1.00$ mmol, $206 \mathrm{mg}$ ) was added and the solution was stirred over night, allowing it to warm up to room temperature slowly. The mixture was extracted with $3 \mathrm{~N} \mathrm{HCl}$ and brine. The organic layer was dried over sodium sulfate and filtered. After solvent evaporation the residue was purified using dry column vacuum chromatography (0$25 \%$ EtOAc in hexane (v/v) in $2 \%$ increments) to yield a clear oil (226 mg, 83\%).

${ }^{1} \mathrm{H}-\mathrm{NMR}\left(\mathrm{CDCl}_{3}, 400 \mathrm{MHz}\right): \delta=8.13(\mathrm{t}, 1 \mathrm{H}, \mathrm{J}=1.5$, e), $7.68(\mathrm{~d}, 2 \mathrm{H}, \mathrm{J}=1.5, \mathrm{f}), 7.35(\mathrm{~d}, 2 \mathrm{H}, \mathrm{a}), 6.32-6.29$ (m, $4 \mathrm{H}, \mathrm{b}, \mathrm{c}), 4.36(\mathrm{~s}, 4 \mathrm{H}, \mathrm{d}), 4.21(\mathrm{t}, 2 \mathrm{H}, \mathrm{J}=4.8, \mathrm{~g})$, $3.88(\mathrm{t}, 2 \mathrm{H}, \mathrm{J}=4.8, \mathrm{~h}), 3.74-3.56(\mathrm{~m}, 8 \mathrm{H}, \mathrm{i}), 3.44(\mathrm{t}, 2$ $\mathrm{H}, \mathrm{j}), 1.56(\mathrm{~m}, 2 \mathrm{H}, \mathrm{k}), 1.31-1.25(\mathrm{~m}, 18 \mathrm{H}, \mathrm{l}), 0.88$ (t, 3 $\mathrm{H}, \mathrm{m}) .{ }^{13} \mathrm{C}-\mathrm{NMR}\left(\mathrm{CDCl}_{3}, 400 \mathrm{MHz}\right): \delta=189.7,159.3$, 150.0, 142.4, 138.3, 118.7, 117.8, 110.7, 108.3, 71.6, 71.0, 70.7, 70.7, 70.0, 69.5, 68.2, 31.9, 29.7, 29.6, 29.5, 29.3, 26.1, 22.7, 14.1. Exact mass calculated: 675.3025 , found: $675.3043\left[\mathrm{M}+\mathrm{H}^{+}\right]$. 
Dimethyl 5-(dimethylcarbamothioyloxy)isophthalate 23 Dimethyl-5-hydroxyisophthalic acid (9.99 mmol, $2.10 \mathrm{~g})$ was dissolved in anhydrous DMF $(10 \mathrm{~mL})$ and cooled to $4{ }^{\circ} \mathrm{C}$. DABCO $(19.97 \mathrm{mmol}, 2.24 \mathrm{~g})$ was added in portions, followed by dropwise addition of a solution of dimethylthiocarbamoyl chloride (19.98 mmol, $2.47 \mathrm{~g}$ ) in anhydrous DMF $(10 \mathrm{~mL})$. The resulting suspension was allowed to warm up to room temperature slowly. After 24 hours the reaction mixture was poured into water $(100 \mathrm{~mL})$ and the precipitate was filtered off and washed with water. Recrystallisation from methanol yielded a white powder (2.32 g, 78\%).

${ }^{1} \mathrm{H}-\mathrm{NMR}\left(\mathrm{CDCl}_{3}, 400 \mathrm{MHz}\right): \delta=8.57(\mathrm{t}, 1 \mathrm{H}, \mathrm{J}=1.5$, b), $7.92(\mathrm{~d}, 2 \mathrm{H}, \mathrm{J}=1.5, \mathrm{c}), 3.93(\mathrm{~s}, 6 \mathrm{H}, \mathrm{a}), 3.45(\mathrm{~s}, 3 \mathrm{H}$, d), $3.36(\mathrm{~s}, 3 \mathrm{H}, \mathrm{d}) .{ }^{13} \mathrm{C}-\mathrm{NMR}\left(\mathrm{CDCl}_{3}, 400 \mathrm{MHz}\right): \delta=$ 187.0, 165.4, 153.9, 131.6, 128.4, 128.0, 52.5, 43.4, 38.8 . Exact mass calculated: 298.0749 , found: $297.0749[\mathrm{M}+\mathrm{H}$ ${ }^{+}$]. Melting point: $105-106^{\circ} \mathrm{C}$.

\section{Dimethyl 5-(dimethylcarbamoylthio)isophthalate 24}

Dimethyl 5-(dimethylcarbamothioyloxy)isophthalate (23; $2.99 \mathrm{mmol}, 890 \mathrm{mg}$ ) was heated at $215^{\circ} \mathrm{C}$ under a $\mathrm{N}_{2}$ atmosphere for 1 hour. The mixture was cooled to about $70^{\circ} \mathrm{C}$ and ethanol $(20 \mathrm{~mL})$ was added. The pale brown crystals that appeared upon cooling down to room temperature were filtered off to give the product (802 $\mathrm{mg}, 90 \%)$.

${ }^{1} \mathrm{H}-\mathrm{NMR}\left(\mathrm{CDCl}_{3}, 400 \mathrm{MHz}\right): \delta=8.69(\mathrm{t}, 1 \mathrm{H}, \mathrm{J}=1.5$, b), $8.34(\mathrm{~d}, 2 \mathrm{H}, \mathrm{J}=1.5, \mathrm{c}), 3.94(\mathrm{~s}, 6 \mathrm{H}, \mathrm{a}), 3.10(\mathrm{~s}, 3 \mathrm{H}$, d), $3.04(\mathrm{~s}, 3 \mathrm{H}, \mathrm{d}) .{ }^{13} \mathrm{C}-\mathrm{NMR}\left(\mathrm{CDCl}_{3}, 400 \mathrm{MHz}\right): \delta=$ $165.5,140.7,131.2,130.5,52.5,37.0$. Exact mass calculated: 298.0749, found: $297.0746\left[\mathrm{M}+\mathrm{H}^{+}\right]$. Melting point: $122-124^{\circ} \mathrm{C}$.

\section{5-Mercaptoisophthalic acid 25}

A 1.2 $\mathrm{M}$ solution of potassium hydroxide in a 1:1 mixture of ethanol and water $(20 \mathrm{~mL})$ was degassed by purging with $\mathrm{N}_{2}$ for at least 2 hours. Dimethyl 5-(dimethylcarbamoyl-thio)isophthalate $(24 ; 2.02 \mathrm{mmol}, 0.60 \mathrm{~g})$ was added and the mixture was stirred at $80^{\circ} \mathrm{C}$ for 30 minutes under nitrogen, and then for another 1.5 hours, allowing it to cool down to room temperature slowly. Addition of concentrated $\mathrm{HCl}(10 \mathrm{~mL})$ led to the precipitation of the product which was filtered off, washed with dilute $\mathrm{HCl}$ $(0.3 \%)$ and dried under vacuum (yield: $0.33 \mathrm{~g}, 83 \%)$.

${ }^{1} \mathrm{H}-\mathrm{NMR}\left(\mathrm{CD}_{3} \mathrm{OD}, 400 \mathrm{MHz}\right): \delta=8.36(\mathrm{t}, 1 \mathrm{H}, \mathrm{J}=$ 1.5, a), 8.11 (d, $2 \mathrm{H}, \mathrm{J}=1.5, \mathrm{~b}) .{ }^{13} \mathrm{C}-\mathrm{NMR}$ ( $\mathrm{CD}_{3} \mathrm{OD}, 400$ $\mathrm{MHz}): \delta=168.2,135.4,134.5,133.3,128.4$. Exact mass calculated: 196.9911 , found: $196.9914\left[\mathrm{M}-\mathrm{H}^{+}\right]$. Melting point: $280-282^{\circ} \mathrm{C}$.

\section{S,S-(5-Mercaptoisophthalic acid) benzene-1,3-bis (carbothioate) 28}

5-Mercaptoisophthalic acid (25; $2.02 \mathrm{mmol}, 0.40 \mathrm{~g})$ and triethylamine $(11.97 \mathrm{mmol}, 1.66 \mathrm{~mL})$ were dissolved in a
1:1 mixture of water and acetonitrile $(50 \mathrm{~mL})$. Isophthaloyl dichloride $(0.99 \mathrm{mmol}, 0.20 \mathrm{~g})$ was added and the solution was stirred at room temperature for 4 hours. The mixture was extracted with hexane three times and after evaporation of the solvent, the residue was redissolved in water. Fractional precipitation by careful addition of $3 \mathrm{~N} \mathrm{HCl}$ gave a white powder which was recrystallised from methanol to yield the product (47 mg, 9\%).

${ }^{1} \mathrm{H}-\mathrm{NMR}$ (DMSO- $\left.d_{6}, 400 \mathrm{MHz}\right): \delta=8.55(\mathrm{t}, 2 \mathrm{H}, \mathrm{J}=$ 1.6, a), $8.46(\mathrm{t}, 1 \mathrm{H}, \mathrm{J}=1.8, \mathrm{c}), 8.34 \mathrm{dd}, 2 \mathrm{H}, \mathrm{J}=7.8, \mathrm{~J}=$ $1.8, \mathrm{~d}), 8.28(\mathrm{~m}, 4 \mathrm{H}, \mathrm{b}), 7.75(\mathrm{t}, 1 \mathrm{H}, \mathrm{J}=7.8, \mathrm{e}) .{ }^{13} \mathrm{C}-$ NMR (DMSO- $\left.d_{6}, 400 \mathrm{MHz}\right): \delta=187.9,165.7,139.2$, 136.3, 132.6, 131.2, 131.1, 130.7, 130.0, 127.9, 127.7, 125.4. Exact mass calculated: 548.9926 , found: 548.9929 $\left[\mathrm{M}+\mathrm{Na}^{+}\right]$. Melting point: $263-265^{\circ} \mathrm{C}$.

\section{Methyl 4-mercaptobenzoate 26}

4-Mercaptobenzoic acid (8.56 mmol, $1.32 \mathrm{~g}$ ) was dissolved in methanol $(40 \mathrm{~mL})$. After addition of concentrated sulfuric acid $(1 \mathrm{~mL})$, the solution was refluxed for 24 hours. The solvent was evaporated and the residue was purified using dry column vacuum chromatography $(0-25 \%$ EtOAc in hexane $(\mathrm{v} / \mathrm{v})$ containing $0.1 \%$ formic acid, in $2 \%$ increments) to yield a white solid (1.43 g, 99\%).

${ }^{1} \mathrm{H}-\mathrm{NMR}\left(\mathrm{CDCl}_{3}, 400 \mathrm{MHz}\right): \delta=7.89(\mathrm{dt}, 2 \mathrm{H}, \mathrm{J}=8.5$, $\mathrm{J}=2.0, \mathrm{~b}), 7.29(\mathrm{dt}, 2 \mathrm{H}, \mathrm{J}=8.5, \mathrm{~J}=2.0, \mathrm{c}), 3.90(\mathrm{~s}, 3 \mathrm{H}$, a), $3.60(\mathrm{~s}, 1 \mathrm{H}, \mathrm{d}) .{ }^{13} \mathrm{C}-\mathrm{NMR}\left(\mathrm{CDCl}_{3}, 400 \mathrm{MHz}\right): \delta=$ 166.6, 138.3, 130.2, 128.1, 127.2, 52.1. Exact mass calculated: 191.0140 , found: $191.0137\left[\mathrm{M}+\mathrm{Na}^{+}\right]$. Melting point: $57-58^{\circ} \mathrm{C}$.

\section{S,S-Bis(methyl-4 benzoate) 5-(2-(2-(2-(dodecyloxy)ethoxy)} ethoxy)ethoxy)benzene-1,3-bis(carbothioate) 30

5-(2-(2-(2-(Dodecyloxy)ethoxy)ethoxy)ethoxy)isophthalic acid (22, $0.40 \mathrm{mmol}, 193 \mathrm{mg})$, methyl 4-mercaptobenzoate (26; $1.00 \mathrm{mmol}, 168 \mathrm{mg})$ and DMAP (0.10 mmol, 12 $\mathrm{mg})$ were dissolved in anhydrous $\mathrm{CH}_{2} \mathrm{Cl}_{2}(10 \mathrm{~mL})$ and cooled to $4^{\circ} \mathrm{C}$ on an ice bath. Dicyclohexylcarbodiimide ( $1.00 \mathrm{mmol}, 206 \mathrm{mg}$ ) was added and the solution was stirred overnight, allowing it to warm up to room temperature slowly. The mixture was extracted with $3 \mathrm{~N}$ $\mathrm{HCl}$ and brine, and the organic layer was dried over sodium sulfate and filtered. After solvent evaporation the residue was purified using dry column vacuum chromatography (0-25\% EtOAc in hexane (v/v) in 2\% increments) to yield a clear oil (180 mg, 35\%).

${ }^{1} \mathrm{H}-\mathrm{NMR}\left(\mathrm{CDCl}_{3}, 400 \mathrm{MHz}\right): \delta=8.26(\mathrm{t}, 1 \mathrm{H}, \mathrm{J}=1.4$, d), $8.13(\mathrm{dt}, 2 \mathrm{H}, \mathrm{J}=8.5, \mathrm{~J}=1.9, \mathrm{~b}), 7.77(\mathrm{~d}, 2 \mathrm{H}, \mathrm{J}=$ $1.5, \mathrm{e}), 7.62(\mathrm{dt}, 2 \mathrm{H}, \mathrm{J}=8.5, \mathrm{~J}=1.9, \mathrm{c}), 4.25(\mathrm{t}, 2 \mathrm{H}, \mathrm{J}=$ 4.6, f), 3.95 (s, $6 \mathrm{H}, \mathrm{a}), 3.92(\mathrm{t}, 2 \mathrm{H}, \mathrm{J}=4.6, \mathrm{~g}), 3.76-$ $3.56(\mathrm{~m}, 8 \mathrm{H}, \mathrm{h}), 3.44(\mathrm{t}, 2 \mathrm{H}, \mathrm{i}), 1.60-1.55(\mathrm{~m}, 2 \mathrm{H}, \mathrm{j})$, $1.32-1.24(\mathrm{~m}, 18 \mathrm{H}, \mathrm{k}), 0.87(\mathrm{t}, 3 \mathrm{H}, \mathrm{l}) .{ }^{13} \mathrm{C}-\mathrm{NMR}$ 
$\left(\mathrm{CDCl}_{3}, 400 \mathrm{MHz}\right): \delta=188.0,166.3,159.6,138.2,134.6$, $132.5,131.2,130.2,118.9,118.3,71.5,70.9,70.7,70.7$, 70.0, 69.5, 68.3, 52.3, 31.9, 29.6, 29.5, 29.3, 26.1, 22.7, 14.1. Exact mass calculated: 783.3237 , found: 783.3263 $\left[\mathrm{M}+\mathrm{H}^{+}\right]$.

\section{Preparation of vesicles}

A solution of $25 \mathrm{mg}$ egg PC in chloroform (1 mL) was placed in a pyrex glass test tube and, where appropriate, a stock solution of one of the amphiphilic thioester building blocks in chloroform was added to give the desired ratio of lipid to thioester. The chloroform was evaporated under a stream of nitrogen to leave a lipid film on the wall of the test tube, which was dried under vacuum over night. Then, $100 \mathrm{mM}$ phosphate buffer $(1.65 \mathrm{~mL})$ was added to give a concentration of $20 \mathrm{mM}$ egg PC and the solution was vortexed for 30 seconds or until the lipid film was completely dispersed. The mixture was allowed to rest, vortexed again for 30 seconds and allowed to rest for 20 minutes. Five freeze-thaw cycles were followed by extrusion through polycarbonate membranes, ten times through $400 \mathrm{~nm}$ pore size and ten times through $200 \mathrm{~nm}$ pore size. The resulting vesicle solution was allowed to rest for one hour before libraries were set up.

\section{Preparation of DCLs}

DCLs in bulk aqueous solution were prepared by dissolving building blocks in $100 \mathrm{mM}$ phosphate buffer to the appropriate concentrations (library volume: $0.5 \mathrm{~mL}$ ) and adjusting the $\mathrm{pH}$ to 8 with $1 \mathrm{M} \mathrm{KOH}$. These stock solutions were mixed to give the final concentrations given in the text.

The libraries were then stirred at $40^{\circ} \mathrm{C}$ for 5 hours, unless otherwise stated, and analysed by HPLC and LCMS.

DCLs at the bilayer interface were prepared by dissolving thiol building blocks in $100 \mathrm{mM}$ phosphate buffer to the appropriate concentrations and adjusting the $\mathrm{pH}$ with $1 \mathrm{M} \mathrm{KOH}$. These stock solutions were then mixed with the freshly prepared vesicle solutions. In some cases, when the thiols to be used were not soluble in water, a highly concentrated stock solution in 2-propanol was prepared and a few microlitres of this were injected into the vesicle solution to give the appropriate final concentration. Libraries were equilibrated at $40^{\circ} \mathrm{C}$ for 24 hours and analysed by HPLC and LC-MS.

Table 3 HPLC gradient A

\begin{tabular}{lll}
\hline Time (mins) & Acetonitrile $(\mathbf{0 . 1} \% \mathrm{FA})$ & Water $(\mathbf{0 . 1} \% \mathrm{FA})$ \\
\hline 0 & 5 & 95 \\
10 & 95 & 5 \\
13 & 95 & 5 \\
\hline
\end{tabular}

Table 4 HPLC gradient B

\begin{tabular}{lll}
\hline Time (mins) & Acetonitrile (0.1\% FA) & Water (0.1\% FA) \\
\hline 0 & 5 & 95 \\
25 & 95 & 5 \\
28 & 95 & 5 \\
\hline
\end{tabular}

\section{HPLC analysis}

HPLC analysis was performed on an Agilent HP 1100 system fitted with an online degasser, quaternary pump, autosampler, heated column compartment and diode array detector set to a wavelength of $260 \mathrm{~nm}$.

DCLs in bulk aqueous solution: Separation of library members in the kinetic studies and libraries shown in Figure $8 \mathrm{a}$ was achieved by injection of $5 \mu \mathrm{l}$ of library solution onto a Zorbax Eclipse XBD-C8 $(150 \times 4.6 \mathrm{~mm}$, $5 \mu \mathrm{m})$ column and elution with a gradient of acetonitrile $(0.1 \%$ formic acid (FA) ) and water $(0.1 \%$ FA) at a flow rate of $2 \mathrm{~mL} / \mathrm{min}$. HPLC gradient A was used (Table 3).

Libraries shown in Figures 4 and 9a were analysed by injecting $5 \mu \mathrm{l}$ of library solution onto a Waters Symmetry C8 column $(150 \times 4.6 \mathrm{~mm}, 3.5 \mu \mathrm{m})$ and eluting with a gradient of acetonitrile ( $0.1 \%$ FA) and water $(0.1 \%$ FA) at a flow rate of $1 \mathrm{~mL} / \mathrm{min}$. HPLC gradient $B$ was used (Table 4).

DCLs at the bilayer interface: Separation of library members was achieved by injection of $5 \mu \mathrm{l}$ of library solution onto a Waters Symmetry C6 $(150 \times 4.6 \mathrm{~mm}, 5$ $\mu \mathrm{m})$ column and elution with a gradient of acetonitrile ( $0.1 \%$ formic acid) and water $(0.1 \%$ formic acid $)$ at a flow rate of $2 \mathrm{~mL} / \mathrm{min}$. HPLC gradient $\mathrm{C}$ was used (Table 5).

\section{LC-MS analysis}

LC-MS analysis was performed using an Agilent HP 1100 system coupled to an Agilent XCT iontrap MSD mass spectrometer. For DCLs in bulk water an injection volume of $2 \mu \mathrm{L}$ was used, while for DCLs at the bilayer interface an injection volume of $0.5 \mu \mathrm{L}$ was used. Mass spectra were acquired in standard-enhanced scan mode using a drying temperature of $335^{\circ} \mathrm{C}$, a nebuliser pressure of $20.0 \mathrm{psi}$, drying gas flow of $6.0 \mathrm{~L} / \mathrm{min}$ and an ICC target of 50,000 ions. The instrument was tuned for the target mass of 1200. Agilent Chemstation software (Rev A.10.02) and Bruker Daltonik LC/MSD Trap software 5.2 (Build 374) was used to operate the LC-MS and analyse the data produced.

Table 5 HPLC gradient $C$

\begin{tabular}{lll}
\hline Time (mins) & Acetonitrile (0.1\% FA) & Water (0.1\% FA) \\
\hline 0 & 5 & 95 \\
20 & 95 & 5 \\
25 & 95 & 5 \\
\hline
\end{tabular}




\section{Additional material}

Additional file 1: PDF. Supporting information. HPLC data for singlesided and double-sided addition of thiols to DCLs at the bilayer interface and LC-MS data for the DCLs shown in Figures 8 and 9.

\section{Acknowledgements}

We are grateful for financial support from the EPSRC and the COST CM0703 action on Systems Chemistry. We thank Dr. Ana Belenguer for help with the HPLC and LC-MS analyses.

\section{Author details}

'Department of Chemistry, University of Cambridge, Lensfield Road, Cambridge, CB2 1EW, UK. ${ }^{2}$ Centre for Systems Chemistry, Stratingh Institute, University of Groningen, Nijenborgh 4, 9747 AG Groningen, The Netherlands.

\section{Authors' contributions}

HYAY prepared dithiol $\mathbf{2 7}$ with the advice of JKMS. FMM performed all other experiments and the data analysis. FMM and SO interpreted the results, developed the conclusions and wrote the manuscript. All authors read and approved the final manuscript.

\section{Competing interests}

The authors declare that they have no competing interests.

Received: 17 June 2010 Accepted: 8 September 2010

Published: 8 September 2010

\section{References}

1. Corbett PT, Leclaire J, Vial L, West KR, Wietor J-L, Sanders JKM, Otto S: Dynamic combinatorial chemistry. Chem Rev 2006, 106:3652-3711.

2. Lehn JM: From supramolecular chemistry towards constitutional dynamic chemistry and adaptive chemistry. Chem Soc Rev 2007, 36:151-160

3. Ladame S: Dynamic combinatorial chemistry: on the road to fulfilling the promise. Org Biomol Chem 2008, 6:219-226.

4. Stankiewicz J, Eckardt LH: Chembiogenesis 2005 and systems chemistry workshop. Angew Chem Int Ed 2006, 45:342-344.

5. Whitesides GM, Ismagilov RF: Complexity in chemistry. Science 1999, 284:89-92.

6. Newth D, Finnigan J: Emergence and self-organization in chemistry and biology. Aust J Chem 2006, 59:841-848.

7. Ludlow RF, Otto S: Systems chemistry. Chem Soc Rev 2008, 37:101-108.

8. Peyralans JJP, Otto S: Recent highlights in systems chemistry. Curr Opin Chem Biol 2009, 13:705-713.

9. Nitschke JR: Systems chemistry: Molecular networks come of age. Nature 2009, 462:736-738.

10. Gibb BC: Teetering towards chaos and complexity. Nat Chem 2009, 1:17-18.

11. Balazs AC, Epstein IR: Emergent or just complex? Science 2009, 325:1632-1634

12. Au-Yeung HY, Pengo P, Pantos GD, Otto S, Sanders JKM: Templated amplification of a naphthalenediimide-based receptor from a donoracceptor dynamic combinatorial library in water. Chem Commun 2009 419-421.

13. Lippert AR, Keleshian VL, Bode JW: Dynamic supramolecular complexation by shapeshifting organic molecules. Org Biomol Chem 2009, 7:1529-1532.

14. Perez-Fernandez $R$, Pittelkow $M$, Belenguer $A M$, Lane LA, Robinson CV Sanders JKM: Two-phase dynamic combinatorial discovery of a spermine transporter. Chem Commun 2009, 3708-3710.

15. Saggiomo V, Lüning U: Transport of calcium ions through a bulk membrane by use of a dynamic combinatorial library. Chem Commun 2009, 3711-3713.

16. Sun JY, Patrick BO, Sherman JC: A new [4]carceplex, and a crystal structure and dynamic combinatorial chemistry of a [5]carceplex. Tetrahedron 2009, 65:7296-7302.

17. Ulrich S, Lehn JM: Adaptation and optical signal generation in a constitutional dynamic network. Chem Eur J 2009, 15:5640-5645.
18. Ulrich S, Lehn JM: Adaptation to shape switching by component selection in a constitutional dynamic system. J Am Chem Soc 2009, 131:5546-5559.

19. Xu XN, Wang L, Wang GT, Lin JB, Li GY, Jiang XK, Li ZT: Hydrogenbonding-mediated dynamic covalent synthesis of macrocycles and capsules: new receptors for aliphatic ammonium ions and the formation of pseudo[3]rotaxanes. Chem Eur J 2009, 15:5763-5774.

20. Leclaire J, Husson G, Devaux N, Delorme V, Charles L, Ziarelli F, Desbois P, Chaumonnot $A$, Jacquin $M$, Fotiadu $F$, Buono $G$ : $\mathrm{CO}_{2}$ binding by dynamic combinatorial chemistry: an environmental selection. J Am Chem Soc 2010, 132:3582-3593.

21. Saggiomo V, Goeschen C, Herges R, Quesada R, Lüning U: lon transport across membranes facilitated by a dynamic combinatorial library. Eur $J$ Org Chem 2010, 2337-2343.

22. Nasr G, Petit E, Vullo D, Winum JY, Supuran CT, Barboiu M: Carbonic anhydrase-encoded dynamic constitutional libraries: toward the discovery of isozyme-specific inhibitors. J Med Chem 2009, 52:4853-4859.

23. Nasr G, Petit E, Supuran CT, Winum JY, Barboiu M: Carbonic anhydrase IIinduced selection of inhibitors from a dynamic combinatorial library of Schiff's bases. Bioorg Med Chem Lett 2009, 19:6014-6017.

24. Scott DE, Dawes GJ, Ando M, Abell C, Ciulli A: A fragment-based approach to probing adenosine recognition sites by using dynamic combinatorial chemistry. ChemBioChem 2009, 10:2772-2779.

25. Vongvilai $P$, Ramström $O$ : Dynamic asymmetric multicomponent resolution: lipase-mediated amidation of a double dynamic covalent system. J Am Chem Soc 2009, 131:14419-14425.

26. Brisig B, Sanders JKM, Otto S: Selection and amplification of a catalyst from a dynamic combinatorial library. Angew Chem Int Ed 2003 42:1270-1273.

27. Vial L, Sanders JKM, Otto S: A catalyst for an acetal hydrolysis reaction from a dynamic combinatorial library. New J Chem 2005, 29:1001-1003.

28. Sadownik JW, Philp D: A simple synthetic replicator amplifies itself from a dynamic reagent pool. Angew Chem Int Ed 2008, 47:9965-9970.

29. Das AK, Hirst AR, Ulijn RV: Evolving nanomaterials using enzyme-driven dynamic peptide libraries (eDPL). Faraday Discuss 2009, 143:293-303.

30. Hunt RAR, Ludlow RF, Otto S: Estimating equilibrium constants for aggregation from the product distribution of a dynamic combinatorial library. Org Lett 2009, 11:5110-5113.

31. Minkenberg CB, Florusse L, Eelkema R, Koper GJM, van Esch JH: Triggered self-assembly of simple dynamic covalent surfactants. J Am Chem Soc 2009, 131:11274-11275.

32. Nguyen R, Allouche L, Buhler E, Giuseppone N: Dynamic combinatorial evolution within self-replicating supramolecular assemblies. Angew Chem Int Ed 2009, 48:1093-1096.

33. Ura Y, Beierle JM, Leman LJ, Orgel LE, Ghadiri MR: Self-assembling sequence-adaptive peptide nucleic acids. Science 2009, 325:73-77.

34. Wang GT, Lin JB, Jiang XK, Li ZT: Cholesterol-appended aromatic imine organogelators: a case study of gelation-driven component selection. Langmuir 2009, 25:8414-8418.

35. Williams RJ, Smith AM, Collins R, Hodson N, Das AK, Ulijn RV: Enzymeassisted self-assembly under thermodynamic control. Nature Nanotech 2009, 4:19-24.

36. Otto S: Molecular self-assembly. Helping themselves. Nature Nanotech 2009, 4:13-14.

37. Orrillo AG, Furlan RLE: Supramolecular interactions between library members modulate the behavior of dynamic combinatorial libraries. J Org Chem 2010, 75:211-214

38. Carnall JMA, Waudby CA, Belenguer AM, Stuart MCA, Peyralans JJP, Otto S: Mechanosensitive self-replication driven by self-organization. Science 2010, 327:1502-1506

39. Au-Yeung HY, Pantos GD, Sanders JKM: Amplifying different [2]catenanes in an aqueous donor-acceptor dynamic combinatorial library. J Am Chem Soc 2009, 131:16030-16032.

40. Chung MK, White PS, Lee SJ, Gagne MR: Synthesis of interlocked 56membered rings by dynamic self-templating. Angew Chem Int Ed 2009, 48:8683-8686.

41. Au-Yeung HY, Pantos GD, Sanders JKM: Dynamic combinatorial synthesis of a catenane based on donor-acceptor interactions in water. Proc Natl Acad Sci USA 2009, 106:10466-10470.

42. Price JL, Hadley EB, Steinkruger JD, Gellman SH: Detection and analysis of chimeric tertiary structures by backbone thioester exchange: packing of 
an alpha helix against an alpha/beta-peptide helix. Angew Chem Int Ed 2010, 49:368-371.

43. Bromley EHC, Sessions RB, Thomson AR, Woolfson DN: Designed alphahelical tectons for constructing multicomponent synthetic biological systems. J Am Chem Soc 2009, 131:928-930.

44. Pomerantz WC, Hadley EB, Fry CG, Gellman SH: In situ monitoring of backbone thioester exchange by F-19 NMR. ChemBioChem 2009, 10:2177-2181.

45. Choudhary S, Morrow JR: Dynamic acylhydrazone metal ion complex libraries: A mixed-ligand approach to increased selectivity in extraction. Angew Chem Int Ed 2002, 41:4096-4098.

46. Ariga K, Kunitake T: Molecular recognition at air-water and related interfaces: Complementary hydrogen bonding and multisite interaction. Acc Chem Res 1998, 31:371-378.

47. Kikuchi Jl, Ogata T, Inada M, Murakami Y: Circular dichroism of an aromatic guest induced by a chiral steroid cyclophane in aqueous solution and synthetic bilayer membrane. Chem Lett 1996, 771-772.

48. Onda M, Yoshihara K, Koyano $\mathrm{H}$, Ariga $\mathrm{K}$, Kunitake $\mathrm{T}$ : Molecular recognition of nucleotides by the guanidinium unit at the surface of aqueous micelles and bilayers. A comparison of microscopic and macroscopic interfaces. J Am Chem Soc 1996, 118:8524-8530.

49. Larsson R, Pei ZC, Ramström O: Catalytic self-screening of cholinesterase substrates from a dynamic combinatorial thioester library. Angew Chem Int Ed 2004, 43:3716-3718.

50. Woll MG, Gellman SH: Backbone thioester exchange: a new approach to evaluating higher order structural stability in polypeptides. J Am Chem Soc 2004, 126:11172-11173.

51. Larsson R, Ramström O: Dynamic combinatorial thiolester libraries for efficient catalytic self-screening of hydrolase substrates. Eur J Org Chem 2005, 285-291.

52. Hadley EB, Gellman SH: An antiparallel alpha-helical coiled-coil model system for rapid assessment of side-chain recognition at the hydrophobic interface. J Am Chem Soc 2006, 128:16444-16445.

53. Woll MG, Hadley EB, Mecozzi S, Gellman SH: Stabilizing and destabilizing effects of phenylalanine -> F-5-phenylalanine mutations on the folding of a small protein. J Am Chem Soc 2006, 128:15932-15933.

54. Hadley EB, Witek AM, Freire F, Peoples AJ, Gellman SH: Thermodynamic analysis of beta-sheet secondary structure by backbone thioester exchange. Angew Chem Int Ed 2007, 46:7056-7059.

55. Lam RTS, Belenguer A, Roberts SL, Naumann C, Jarrosson T, Otto S, Sanders JKM: Amplification of acetylcholine-binding catenanes from dynamic combinatorial libraries. Science 2005, 308:667-669.

56. Podhradsky D, Drobnica L, Kristian P: Reactions of cysteine, its derivatives, glutathione, coenzyme $A$, and dihydrolipoic acid with isothiocyanates. Cell Mol Life Sci 1979, 35:154-155.

57. Danehy JP, Noel CJ: The relative nucleophilic character of several mercaptans toward ethylene oxide. J Am Chem Soc 1960, 82:2511-2515.

58. Kuzmic P: Program DYNAFIT for the analysis of enzyme kinetic data: Application to HIV proteinase. Anal Biochem 1996, 237:260-273.

59. Connors KA, Bender ML: Kinetics of alkaline hydrolysis and $n-$ butylaminolysis of ethyl p-nitrobenzoate and ethyl p-nitrothiolbenzoate. J Org Chem 1961, 26:2498-2504.

60. Brown RS, Aman A: Intramolecular catalysis of thiol ester hydrolysis by a tertiary amine and a carboxylate. J Org Chem 1997, 62:4816-4820.

61. Hupe DJ, Jencks WP: Nonlinear structure-reactivity correlations - acyl transfer between sulfur and oxygen nucleophiles. J Am Chem Soc 1977, 99:451-464.

62. Pohl ER, Wu D, Hupe DJ: Effect of solvation on beta-values for formyl, acetyl, and pivaloyl transfer between sulfur and oxygen nucleophiles. $J$ Am Chem Soc 1980, 102:2759-2763.

63. Epand RM, Kraayenhof R: Fluorescent probes used to monitor membrane interfacial polarity. Chem Phys Lipids 1999, 101:57-64.

64. Mazeres S, Schram V, Tocanne JF, Lopez A: 7-Nitrobenz-2-oxa-1,3-diazole4-yl-labeled phospholipids in lipid membranes: differences in fluorescence behavior. Biophys J 1996, 71:327-335.

65. Doyle EL, Hunter CA, Phillips HC, Webb SJ, Williams NH: Cooperative binding at lipid bilayer membrane surfaces. J Am Chem Soc 2003, 125:4593-4599.

66. Au-Yeung HY, Cougnon FBL, Otto S, Pantos GD, Sanders JKM: Exploiting donor-acceptor interactions in aqueous dynamic combinatorial libraries: exploratory studies of simple systems. Chem Sci 2010, 1.
67. Corbett PT, Sanders JKM, Otto S: Exploring the relation between amplification and binding in dynamic combinatorial libraries of macrocyclic synthetic receptors in water. Chem Eur J 2008, 14:2153-2166.

68. Tecilla P, Jubian V, Hamilton AD: Synthetic hydrogen bonding receptors as models of transacylase anezymes. Tetrahedron 1995, 51:435-448.

\section{doi:10.1186/1759-2208-1-12}

Cite this article as: Mansfeld et al:: Dynamic combinatorial chemistry at the phospholipid bilayer interface. Journal of Systems Chemistry 2010 1:12.

Publish with ChemistryCentral and every
scientist can read your work free of charge
"Open access provides opportunities to our
colleagues in other parts of the globe, by allowing
anyone to view the content free of charge."
W. Jeffery Hurst, The Hershey Company.
- available free of charge to the entire scientific community
- peer reviewed and published immediately upon acceptance
- cited in PubMed and archived on PubMed Central
- yours - you keep the copyright
submit your manuscript here:
http://www.chemistrycentral.com/manuscript/

